Revista Internacional de Apoyo a la Inclusión, Logopedia, Sociedad y Multiculturalidad.

Volumen 4, Número 1, Enero 2018, ISSN: 2387-0907, Dep. Legal: J-67-2015

http://riai.jimdo.com/

\title{
História e Tecnologia: Aliados na resolução de equações do primeiro grau ensino aprendizagem da geometria analítica.
} (History and Technology: Allied in solving equations of the first grade teaching
learning of analytical geometry.)

Elisangela Dias Brugnera
Universidade do Estado do Mato Grosso (UNEMAT).

Fecha recepción: 01-11-2017

Páginas 46-60

Fecha aceptación: 01-12-2017

\section{Resumo.}

Este artigo integra a pesquisa de doutorado quanto o uso da História da Matemática e do GeoGebra para o ensino da geometria analítica com ênfase no estudo de retas do doutorado da REAMEC. 0 qual buscou uma metodologia alternativa para a resolução de equações algébricas do segundo grau. Adotou-se o livro "a geometria" de Descartes, como fonte original aliada a utilização da tecnologia com o software de geometria dinâmica GeoGebra. As bibliografias de Boero, Pedemonte e Robotti, ainda, as representações semióticas de Duval, desenvolveram uma conexão entre 0 passado e o presente, para assim construir um diálogo de novos ressignificado conceitos do passado e do presente tendo como base o comportamento, a tecnologia e as concepções sócio culturais. Contudo, a investigação aponta para a diversificação de metodologias no ensino da matemática, bem como, a multiplicidade de estratégias que podem ser realizadas integrando a história da matemática e as tecnologias.

Palavras-Chaves: ensino; matemática; história, tecnologia; estratégias

\section{Abstract.}

This article integrates the doctoral research on the use of the History of Mathematics and GeoGebra for the teaching of analytical geometry with emphasis on the study of REAMEC doctoral studies. Which sought an alternative methodology for the resolution of algebraic equations of the second degree. We adopted the book "the geometry" of Descartes, as an original source allied to the use of technology with GeoGebra dynamic geometry software. The bibliographies of Boero, Pedemonte, and Robotti, as well as the semiotic representations of Duval, have developed a connection between the past and the present, in order to construct a dialogue of new re-signified concepts of the past and the present, based on behavior, technology and socio-cultural conceptions. However, the research points to the diversification of methodologies in mathematics teaching, as well as the multiplicity of strategies that can be realized integrating the history of mathematics and technologies

Keywords: teaching; mathematics; history, technology; strategies 


\section{1.-Introdução.}

Várias pesquisas visando à integração da história da matemática e dos recursos tecnológicos utilizados no ensino da matemática revelaram que o poder da representação múltipla é ferramenta poderosa para a construção do conhecimento (Thomaidis, 1991; Isoda, 2000; Silva e Sad, 2007; Miguel e Miorim, 2011). A presente investigação insere-se nessa perspectiva e apresenta uma metodologia alternativa para a resolução de equações algébricas, integrando a história da matemática e recursos tecnológicos como o software GeoGebra e a Teoria das representações semióticas de Duval (2011).

Assim sendo, o aluno apenas decora e reproduz as resoluções que o professor apresenta. Essa lacuna na formação dos alunos poderia ser preenchida com 0 desenvolvimento de algumas atividades, que visassem, por exemplo, à habilidade de relacionar a história da Matemática e 0 desenvolvimento da sociedade, 0 pensamento indutivo e dedutivo, formular perguntas e encontrar os resultados.

O objetivo geral da pesquisa de doutorado visa compreender como a historicidade, as relações teórico-práticas e o uso do software GeoGebra no ensino da Geometria Analítica podem contribuir para melhorar a compreensão ou ressignificação dos conceitos de ponto, coordenadas e equação da reta no aprendizado dos alunos. № presente trabalho, com o intuito de exemplificar como a história da Matemática e a tecnologia podem estar integradas na educação matemática, utilizamos, num projeto piloto, o método geométrico de Descartes para a resolução de equações do $1^{\circ}$ grau.

Para o êxito neste projeto, procurou-se realizar uma revisão da literatura que abordasse a resolução das equações do $1^{\circ}$ grau, sob o enfoque geométrico, fazendo uso de fontes históricas originais, como a Geometria de Descartes. Para desenvolver as atividades, os participantes do projeto piloto fizeram uso do software GeoGebra, a fim de realizar as construções geométricas. Com a prática do projeto piloto foi possível testarmos a viabilidade de utilizar tal metodologia em sala de aula.

Não se pode esquecer de que a aprendizagem está vinculada à história do homem, à sua construção e evolução enquanto ser social com capacidade de adaptação a novas situações.

Para que a aprendizagem provoque uma efetiva mudança de comportamento e amplie cada vez mais o potencial do estudante, é necessário que ele perceba a relação entre o que está aprendendo e a sua vida, ou seja, o sujeito precisa ser capaz de reconhecer as situações em que aplicará o novo conhecimento ou habilidade.

Mas a inserção do modo como está sendo realizada nas escolas, acrescida de dificuldades relacionadas à infraestrutura, tem dificultado esse processo de integração e incorporação das tecnologias no ambiente escolar. Essas inserções da 
tecnologia têm levado a mudanças, mesmo que modestas, na prática docente, mas que ainda estão fortemente atreladas aos métodos tradicionais de ensino.

Um ponto importante para utilizar software e recursos digitais como metodologia de ensino é, primeiramente, identificar as potencialidades desse software e em qual contexto podemos utilizá-lo, integrado com as atividades trabalhadas em sala de aula. Assim, teremos uma maior integração entre o conteúdo ministrado em aula e as ações realizadas com 0 software, permitindo que 0 aluno desenvolva diferentes olhares sobre um determinado problema.

Segundo Isoda (2000) muitos exemplos históricos indicam as seguintes funções das ferramentas de investigação: a) Determinar o objeto da investigação matemática; b) Indicar um método matemático para pesquisa; c) Revelar os obstáculos epistemológicos inerentes ao uso dessas ferramentas em um contexto específico ( $p$. 352). Neste contexto, abordado pelo autor, as ferramentas utilizadas na investigação matemática são reformuladas em representações matemáticas: algébricas e geométricas.

Pode-se afirmar que, a partir da revolução científica, os matemáticos procuraram selecionar, localizar ou construir novas representações e instrumentos mais convenientes para as suas pesquisas. Seguindo o modelo adoptado pelos matemáticos, podemos dar aos alunos a oportunidade de escolher, encontrar ou criar novas ferramentas ou representações para a construção do conhecimento.

O aluno, por meio do pensamento reflexivo, realiza conjecturas propiciadas por essas tecnologias digitais. Por meio desses recursos os alunos estabelecem novas condições de interpretação de fenômenos reais, representados matematicamente, perpassando por várias formas de representação dessas condições, sejam por meio de instrumentos como papel, lápis, régua e compasso, ou por recursos digitais, fazendo com que este aluno estabeleça novas condições e interpretações para a construção do conhecimento.

Isoda (2000) percebeu que ao fazer uso de ferramentas digitais como o CAS (Sistema Álgebra Computacional) ou software de geometria dinâmica, os alunos notavam a correspondência visual entre representações geométricas de movimento e representações gráficas estáticas, o surgimento das mesmas equações, seja por diferenciação ou pelo raciocínio geométrico, a correspondência entre os dados de medição e os resultados matemáticos e assim por diante.

Deste modo, a tecnologia pode ajudar os alunos a compreender mais profundamente tanto a história, quanto a matemática. Quando os alunos leem a Geometria de Descartes com base em seus conhecimentos matemáticos, eles podem apresentar dificuldades em entendê-la, porque estão começando a estudar 0 assunto, considerando que a linguagem é antiga e os métodos utilizados, são desconhecidos. 
O uso da tecnologia não objetiva levar os alunos de volta ao pensamento de Descartes, mas ampliar a sua consciência, o seu conhecimento acerca da riqueza da matemática e as suas raízes. Uma das principais preocupações pedagógicas, por muitos anos, tem sido de que os alunos perderam a oportunidade de experimentar as intuições geométricas clássicas.

\section{2.-Bases teórico-metodológicas.}

Neste contexto observou-se que a História da Matemática não é linear, mas que a construção de conceitos depende de um contexto, de um determinado tempo, que favoreceu, como no caso de Descartes, Oresme, Fermat e tantos outros, o avanço da matemática.

A perspectiva sociocultural de Jogos de Vozes e Ecos de Boero, Pedemontti, Robotti (1997) busca uma conexão entre o passado e o presente, considerando suas representações, seus contextos históricos e sociais e seus significados próprios, sem que haja algum tipo de superioridade de um sobre o outro, mas sim, um diálogo. Para nós, é intangível o significado real de um conceito, no passado. 0 que podemos fazer é redimensioná-lo, no presente, utilizando como base nosso comportamento, nossas ferramentas tecnológicas e nossas concepções socioculturais históricas.

Para Boero, Pedemonti, Robotti (1997) e equipe de pesquisadores, a escola era a responsável pela transmissão do conhecimento matemático, ou seja, questões teóricas e sistemáticas, que não são encontradas no cotidiano. A transmissão desse conhecimento se daria pelas condições dadas a estes estudantes, a fim de apropriarem-se das características desse conhecimento teórico-matemático. Os Jogos de Vozes e Ecos seriam as atividades que mediariam e permitiriam que essa apropriação se concretizasse, por criarem um ambiente dialógico de aprendizagem.

Para estes autores, a "voz" é toda a expressão verbal ou não verbal, produzida por cientistas do passado, que proporcionaram as revoluções científicas nas áreas das ciências. Esses importantes saltos históricos na evolução da Matemática e da Ciência, funcionariam como veículos de informações, de conteúdo, da cultura, do discurso, do método, desses saltos.

Quando tais Vozes são apropriadas e ressignificado por pessoas de outras épocas e de outros contextos, diz-se que produzem Ecos. Um eco é, portanto, uma conexão remota estabelecida entre pessoas de diferentes épocas e culturas com base em seus diferentes propósitos, experiências, concepções e sentidos. (MIGUEL; MIORIN, 2011, p.141)

Desta maneira dizemos que Eco é uma forma de ligação estabelecida entre pessoas de diferentes épocas e culturas com base em seus diferentes propósitos, experiências, concepções e sentidos, ou seja, a interpretação que é dada a essa Voz. 
Revista Internacional de Apoyo a la Inclusión, Logopedia, Sociedad y Multiculturalidad. Volumen 4, Número 1, Enero 2018, ISSN: 2387-0907, Dep. Legal: J-67-2015

http://riai.jimdo.com/

\section{3.-Discussão dos resultados do projeto piloto.}

Abordamos neste tópico uma discussão sobre a resolução de equações algébricas do $1^{\circ}$ e $2^{\circ}$ graus, por meio do método geométrico, ou seja, outra maneira de resolver as equações algébricas fazendo uso da geometria plana, como realizado por René Descartes, (1501 - 1576). Foi utilizado o software de geometria dinâmica GeoGebra para a realização das construções geométricas.

Nosso Projeto Piloto foi executado em uma oficina de 25 horas, com alunos do curso de Licenciatura em Matemática da Universidade do Estado de Mato Grosso UNEMAT, que estavam participando do projeto PIBID - Programa Institucional de Bolsa de Iniciação à Docência. Acreditamos que, desta maneira, estarmos atingindo a formação inicial dos futuros professores de matemática, assim como, também, influenciando suas práticas dentro das escolas, onde desenvolvem as atividades do PIBID. Apresentamos as ações realizadas no Projeto Piloto, descritas no quadro1.

Quadro 1: Resumo Atividades desenvolvidas durante a realização do Projeto Piloto.

\begin{tabular}{|c|c|c|c|}
\hline Aula1 & Data & C.H & Objetivos \\
\hline \multirow[t]{5}{*}{1} & $24 / 01 / 2016$ & \multirow[b]{4}{*}{2} & Apresentar a proposta da oficina \\
\hline & & & Discutir questões relacionadas com a utilização da \\
\hline & & & História da Matemática em Sala de Aula \\
\hline & & & Tendências Metodológicas no ensino da Matemática \\
\hline & & 3 & Oficina do GeoGebra \\
\hline 2 & $25 / 01 / 2016$ & 5 & Oficina do GeoGebra \\
\hline \multirow[t]{5}{*}{3} & \multirow[t]{5}{*}{$26 / 01 / 2016$} & \multirow[b]{3}{*}{2} & Nicole D' Oresme (1323-1382) - História, Obra, Descobertas \\
\hline & & & Texto1: O sistema de coordenadas: Oresme, Descartes e Fermat \\
\hline & & & Resolução das questões do ENEM - Relacionadas a coordenadas. \\
\hline & & & Questões do Enem 2010 - N 142 \\
\hline & & 3 & Questões do Enem 2015 - N 156 \\
\hline \multirow[t]{6}{*}{4} & \multirow[t]{6}{*}{$27 / 06 / 2016$} & \multirow[b]{6}{*}{5} & René Descartes - Trabalhar vida, obra, o seu papel no \\
\hline & & & desenvolvimento da Geometria Analitica. \\
\hline & & & Slides Oficina de Descartes e Oficina de Fermat \\
\hline & & & Familializar-se com a obra " A Geometria" (páginas 221- 335) \\
\hline & & & Desenvolver exercícios que utilizem a abordagem histórica \\
\hline & & & de Descartes sobre segmentos de reta no Geogebra. \\
\hline \multirow[t]{7}{*}{5} & \multirow[t]{7}{*}{$28 / 06 / 2016$} & \multirow{7}{*}{ 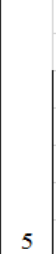 } & Realizar a resolução das questões do Enen - Relacionadas a \\
\hline & & & Equações da reta, coordenadas e pontos. \\
\hline & & & Questões do Enem 2009 - N 159 \\
\hline & & & Questões do Enem 2010- N 146 \\
\hline & & & Questões do Enem 2012 - N 166 \\
\hline & & & Questões do Enem 2011 - N 150 \\
\hline & & & Questões do Enem $2013-\mathrm{N}^{\circ} 175$ \\
\hline
\end{tabular}

Fonte: Dados da pesquisa.

No penúltimo dia da oficina apresentou o Livro I: A Geometria de Descartes, primeiramente os alunos realizaram uma leitura de como Descartes realizava a multiplicação e a divisão de segmentos de reta e como se extraia a raiz quadrada de um segmento. 
A multiplicação: Seja, por exemplo, $A B$ a unidade, multiplicou-se BD por BC; não tenho mais do que unir os pontos $\mathrm{A}$ e $\mathrm{C}$, e traçar $\mathrm{DE}$ paralela a $\mathrm{CA}$, e $\mathrm{BE}$ é o produto desta multiplicação.

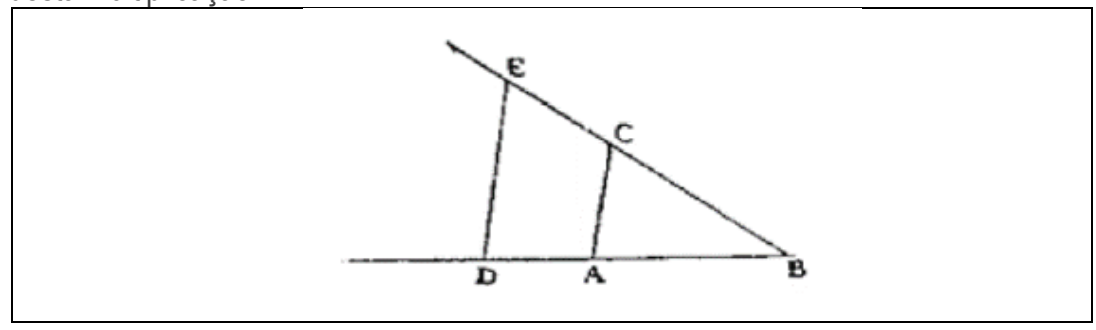

A divisão: Do mesmo modo, se pretendeu dividir $\mathrm{BE}$ por $\mathrm{BD}$, tendo unido os pontos $\mathrm{E}$, e $\mathrm{D}$, traça-se $\mathrm{AC}$ paralela a $\mathrm{DE} ; \mathrm{BC}$ é o resultado desta divisão. A extração da raiz quadrada

Se se pretende extrair a raiz quadrada de $\mathrm{GH}$, se junta em linha reta $\mathrm{FG}$, que é a unidade, e dividindo $\mathrm{FH}$ em duas partes iguais pelo ponto $\mathrm{K}$, tomando esse ponto como centro, traça-se um círculo $\mathrm{FIH}$; elevando então desde o ponto $\mathrm{G}$ uma linhareta, formando ângulos retos com FH, até I, é GI é a raiz buscada. (DESCARTES 2001, p.5).

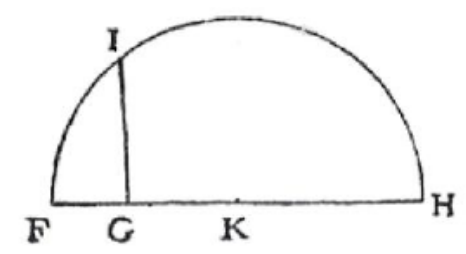

Na realização de alguns exercícios que utilizou-se adição, subtração, multiplicação, divisão e raiz quadrada entre dois segmentos, os alunos explanaram que foi bastante ilustrativo este método e, que não o conheciam. Durante a realização destas atividades, os alunos tiveram a oportunidade de testar o método de resolução geométrico proposto por Descartes, para segmentos de comprimentos distintos.

Pensando no cotidiano escolar, propusemos aos alunos a resolução de várias equações utilizando o método geométrico de Descartes. Apresentamos, na figura 1, a resolução de um aluno da $4^{\circ}$ fase. a) $3 x-6=0$ 
Figura 1: Resolução da equação $3 x-6=0$, segundo o método geométrico Descartes.

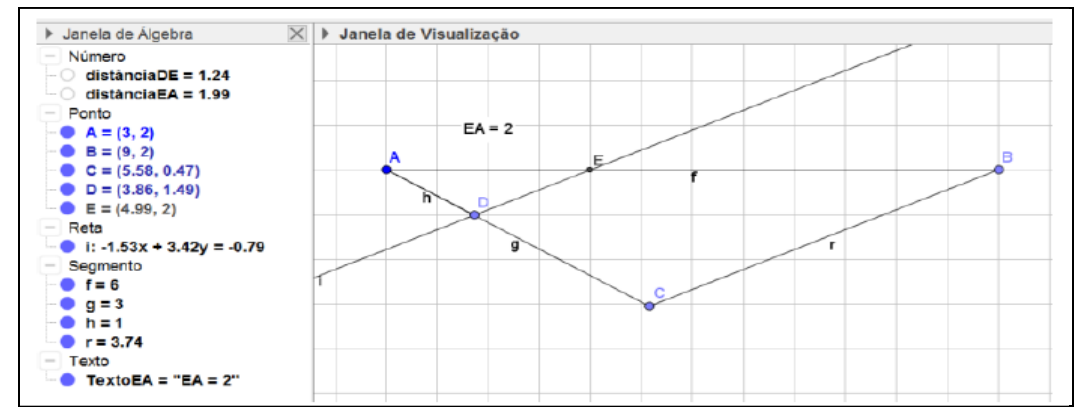

Fonte: Dados da Pesquisa.

A resolução de equações do $2^{\circ}$ grau, segundo o método de Descartes, inicia com a resolução de um tipo particular de equação: $z 2=a z+b 2$

Essa atividade propõe a construção de um triângulo retângulo e também de uma circunferência de raio igual ao cateto menor do triângulo. Por meio desta construção conseguimos determinar as raízes da equação.

E então, esta raiz ou linha desconhecida, encontra-se facilmente. Se tivermos, por exemplo, $z^{2}=a z+b^{2}$ Construo $o$ triângulo retângulo NLM, cujo lado LM é igual $a \mathrm{~b}$, raiz quadrada da quantidade conhecida $b 2$, e o LN é $a 2$, a metade da outra quantidade conhecida, que está multiplicada por Z, que suponho ser a linha desconhecida. Logo, prolongando $\mathrm{MN}$, base desse triângulo, até $\mathrm{O}$, de modo que $\mathrm{NO}$ seja igual a NL, a linha total OM, ou Z, que é a linha buscada Descartes (2003, p.11).

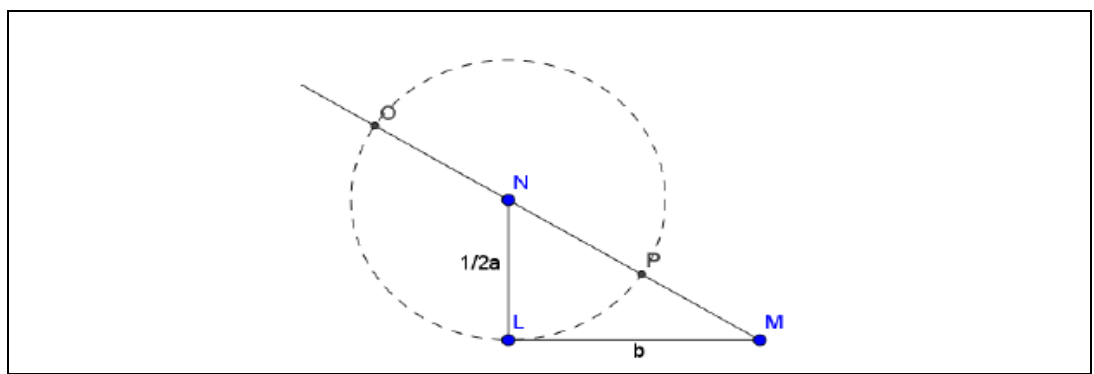

Ainda como 0 autor: Enfim tendo $z^{2}=a z-b^{2}$, faz-se NL igual a 12a, e LN igual a $b$, como anteriormente; logo, 


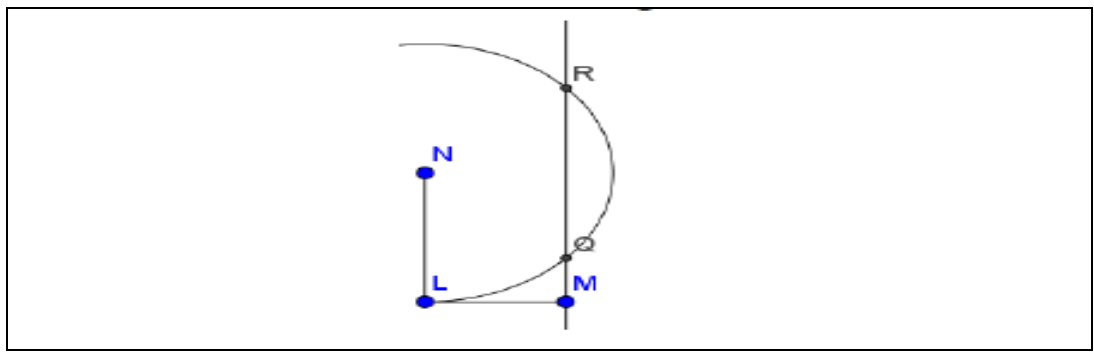

Em vez de unir os pontos $M$ e $N$, traça-se a paralela $M Q R$ a $L N$ e o círculo com 0 centro em $\mathrm{N}$ e que passa por $\mathrm{L}$, que corta nos pontos $\mathrm{Q}$ e $\mathrm{R}$; a linha buscada, $\mathrm{z}$, é $\mathrm{MQ}$ ou MR, pois neste caso ela expressa-se de duas formas, a saber. (Descartes, 2003, p.13)

Propusemos a resolução de algumas equações aos alunos. Como ilustração, apresentamos a resolução de um aluno da $3^{\circ}$ Fase (nas figuras $2 \mathrm{e} 3$ ).

a) $x^{2}+16 x+9=0$

Figura 1:Resolução equação $x^{2}+16 x+9=0$, segundo o método geométrico de Descartes.

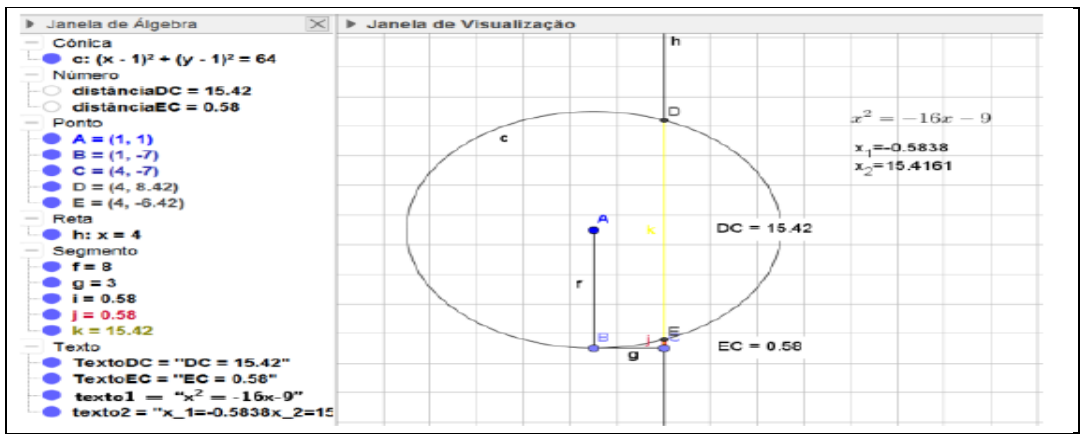

Fonte: Dados da pesquisa.

b) $x^{2}+7 x+9=0$

Figura 2:Resolução da equação $x^{2}+7 x+9=0$, segundo 0 método geométrico de Descartes.

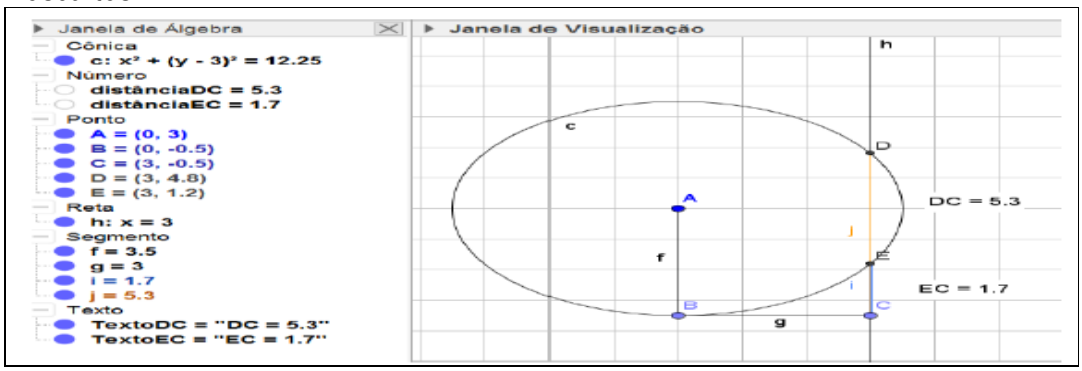

Fonte: Dados da pesquisa. 
Os alunos participantes da oficina relataram que foi uma experiência significativa, pois não tinham realizado anteriormente nenhuma atividade semelhante a esta e que foi possível compreender e visualizar como os processos algébricos podem ser construídos geometricamente. Para a realização desta atividade os alunos precisaram de uma hora e vinte minutos para desenvolver, pelo menos, um experimento de cada operação. Posteriormente demos início à resolução das questões do Enem.

Problema 1: Trajetória do Foguete.

ENEM 2010 - (Caderno 7 - Azul, p. 20) Questão 142 - Um foguete foi lançado do marco zero de uma estação e após alguns segundos atingiu a posição $(6,6,7)$ no espaço, conforme mostra a figura. As distâncias são medidas em quilômetros.

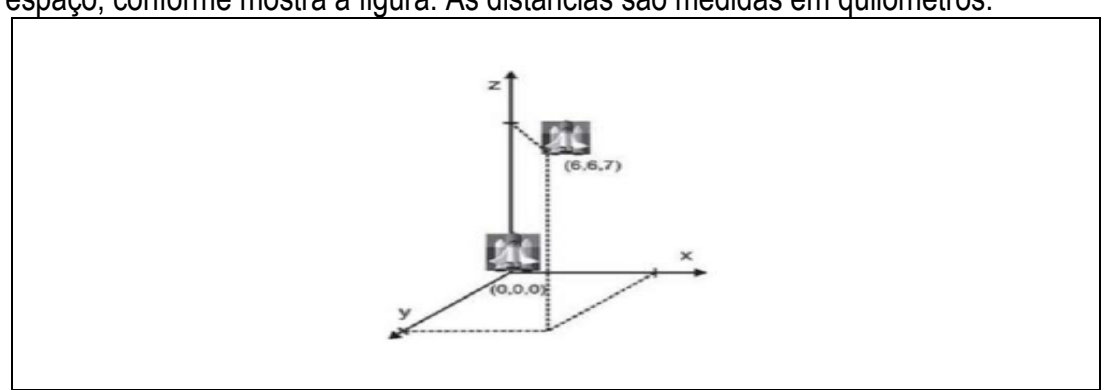

Considerando que o foguete continuou sua trajetória, mas se deslocou $2 \mathrm{~km}$ para a frente na direção do eixo-x, $3 \mathrm{~km}$ para trás na direção do eixo-y, e $11 \mathrm{~km}$ para a frente, na direção do eixo-z, então, o foguete atingiu a posição $(17,3,9)$ b) $(8,3,18)$ c) $(6,18,3)$ d) $(4,9,-4)$ e) $(3,8,18) \operatorname{ENEM}(2010$, p. 20).

Obtivemos resoluções diferenciadas entre os sujeitos. Apresentaremos na sequência as resoluções para o problema e teceremos nossa discussão.

Resolução 1: Apresentada por Ana do P1.

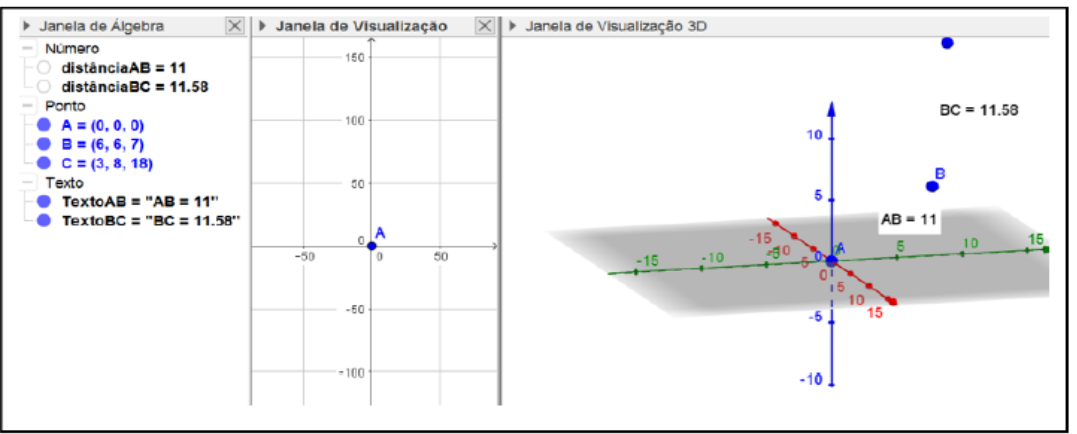

Fonte: Dados da pesquisa. 
RAVP1: Ana

Sem o software é preciso uma interpretação para ver o deslocamento do foguete e o GeoGebra facilita pois agiliza, você joga os dados e ele já constrói. Mas precisa saber manusear. Prefiro usar a ferramenta.

Quadro 1: Registros de Representações Semióticas encontradas nas atividades da acadêmica Ana em P1.

\begin{tabular}{|l|l|}
\hline Figural & Não encontramos nenhum registro na resolução da aluna que ilustre este campo. \\
\hline Gráfica & $\begin{array}{l}\text { A aluna realizou representações e construções no plano cartesiano utilizando a } \\
\text { ferramenta GeoGebra para representar a trajetória do foguete. Marcando os } \\
\text { Pontos que correspondessem ao deslocamento do foguete. }\end{array}$ \\
\hline $\begin{array}{l}\text { Linguagem } \\
\text { Natural }\end{array}$ & $\begin{array}{l}\text { A aluna argumenta que você joga os dados no software e o programa já realiza } \\
\text { a construção, facilitando a compreensão do problema. }\end{array}$ \\
\hline Simbólica & $\begin{array}{l}\text { A aluna utilizou as representações dos pontos para apresentar o deslocamento } \\
\text { do foguete, representando as coordenadas. }\end{array}$ \\
\hline
\end{tabular}

Fonte: Dados da pesquisa.

Resolução 2: Apresentada por Maria do P1.

$$
\begin{aligned}
& x=(6+2)=8 \quad \text { Realizei as operações nos eixos conforme informações. } \\
& y=(6-3)=3 \\
& z=(7+11)=18
\end{aligned}
$$

Fonte: Dados da pesquisa.

RAVP2: Maria

Resolvi realizando as operações que o problema informava, considerei para frente como soma e para trás como subtração. Então foi fácil responder à questão.

Quadro 2: Registros de Representações Semióticas encontradas nas atividades da acadêmica Maria em P1.

\begin{tabular}{|c|c|}
\hline Figural & $\begin{array}{l}\text { Não encontramos nenhum registro na resolução da aluna que ilustre } \\
\text { este campo. }\end{array}$ \\
\hline Gráfica & $\begin{array}{l}\text { Não encontramos nenhum registro na resolução da aluna que ilustre } \\
\text { este campo. }\end{array}$ \\
\hline Latural & $\begin{array}{c}\text { A aluna utilizou-se da linguagem natural para explicar qual tipo de } \\
\text { estratégia fez uso para resolver o problema proposto. }\end{array}$ \\
\hline Simbólica & A aluna resolveu o exercício por meio de equaçōes algébricas. \\
\hline
\end{tabular}

Fonte: Dados da pesquisa. 
Resolução 1:Apresentada por Pedro do P1.

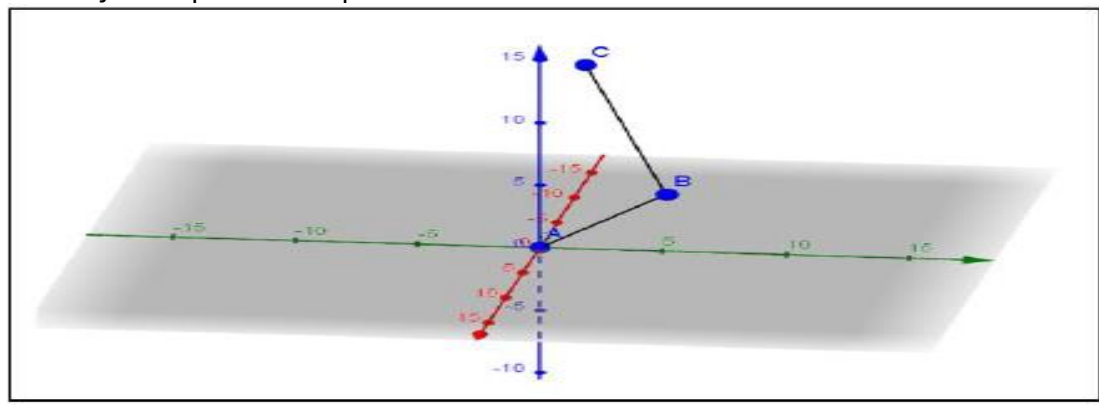

Fonte: Dados da pesquisa.

\section{RAVP1:Pedro}

Primeiramente resolvi por dedução, conforme as informações que eu tinha do problema. Onde cheguei a resposta $(8,3,13)$ ou seja a alternativa $b$.

Achei mais fácil e mais rápido fazer algebricamente, mas no software a gente enxerga que o deslocamento do foguete não é em linha reta e que mesmo unindo os pontos com retas elas poderiam ser curvas. Acho que o programa contribui para visualizarmos isso.

Quadro 3:Registros de Representações Semióticas encontradas nas atividades do acadêmico Pedro em P1.

\begin{tabular}{|c|c|}
\hline Figural & $\begin{array}{c}\text { Não encontramos nenhum registro na resolução do aluno que ilustre } \\
\text { este campo. }\end{array}$ \\
\hline Gráfica & $\begin{array}{c}\text { O aluno realizou representações e construções no plano cartesiano } \\
\text { utilizando a ferramenta GeoGebra para representar a trajetória do foguete. } \\
\text { Marcando os pontos que correspondessem ao deslocamento do foguete. }\end{array}$ \\
\hline $\begin{array}{c}\text { O } \text { Oaluno relata que primeiramente deduziu o resultado para depois } \\
\text { Latural }\end{array}$ & $\begin{array}{c}\text { A aluno O aluno utilizou as representações dos pontos (coordenadas) } \\
\text { utilizar o software para resolver o problema. }\end{array}$ \\
\hline Simbólica & $\begin{array}{l}\text { para apresentar o deslocamento do foguete e traçou a trajetória de } \\
\text { deslocamento do foguete no software GeoGebra. }\end{array}$ \\
\hline
\end{tabular}

Fonte: Dados da pesquisa.

Resolução 2: Resolução André P1.

Eixo $\mathrm{x}=2 \mathrm{~km}$

Eixo $\mathrm{y}=3 \mathrm{~km}$

Resolvi deduzindo

Eixo $\mathrm{z}=11 \mathrm{~km}$

Fonte: Dados da pesquisa. 
RAVP1: André

Nesse caso como é um exercício fácil de resolver eu prefiro resolver algebricamente, pois é só somar e subtrair. Acho que o software ajudaria para visualizar.

Quadro 4: Registros de Representações Semióticas encontradas nas atividades do acadêmico André em P1.

\begin{tabular}{|c|c|}
\hline Figural & $\begin{array}{c}\text { Não encontramos nenhum registro na resolução do aluno que ilustre } \\
\text { este campo. }\end{array}$ \\
\hline Gráfica & $\begin{array}{l}\text { Não encontramos nenhum registro na resolução do aluno que ilustre } \\
\text { este campo. }\end{array}$ \\
\hline $\begin{array}{c}\text { Linguagem } \\
\text { Natural }\end{array}$ & $\begin{array}{l}\text { O aluno relata que primeiramente resolveu o problema deduzindo e } \\
\text { que tem preferência pela resolução algébrica. }\end{array}$ \\
\hline Simbólica & $\begin{array}{c}\text { O aluno utilizou expressões algébricas para resolver os exercícios } \\
\text { propostos no problema. }\end{array}$ \\
\hline
\end{tabular}

Fonte: Dados da pesquisa.

Ana fez uma leitura do exercício e deduziu a resposta, não realizou nenhum cálculo para resolver o problema 1. Ela fez uso do GeoGebra com três janelas abertas simultaneamente: a janela de álgebra, a janela de visualização e a janela 3D. Assim, no momento em que deu a entrada dos dados, ou seja, das coordenadas, automaticamente observava as representações dadas nas outras janelas de visualização.

Maria e André, por sua vez, acharam mais interessante resolver algebricamente, pois não perdiam tempo com a utilização do programa, ambos relataram que o exercício era relativamente fácil e não haveria necessidade de utilização do programa para resolver.

Pedro respondeu à questão utilizando a janela de visualização $3 \mathrm{D}$, mas primeiramente deduziu a resposta e utilizou o software para construir o gráfico do deslocamento do foguete. Os alunos não se sentiram obrigados a utilizar o software, justificaram de maneira muito lógica, pois se era mais rápido resolver algebricamente não seria necessário o uso do procedimento geométrico, a não ser que preferissem uma visualização.

Observamos nas resoluções dos alunos que prevaleceram os registros Monofuncionais, ou seja, são aqueles onde empregamos o tratamento algoritmável. Isso pôde ser constatado, pois os alunos trouxeram em suas resoluções 0 aspecto dedutivo, baseando-se, muitas vezes, nas definições para resolver os problemas propostos. Realizaram associações entre os conceitos, ao serem questionados sobre a forma que utilizaram na resolução do problema e também pelas construções geométricas que trouxeram nas resoluções.

Destacamos a importância do aluno se apropriar dessas diversas formas de representação dos registros semióticos, mas só isso não garante que o aluno 
compreendeu o conceito matemático envolvido, é necessário que estabeleça uma relação entre essas representações e o objeto matemático que está estudando, levando-o a uma melhor compreensão.

Quadro 5: Síntese das Representações Semióticas apresentadas pelos alunos no problema P1.

\begin{tabular}{|l|l|}
\hline \multicolumn{1}{|c|}{ Aluno } & \multicolumn{1}{c|}{ Representações Semióticas } \\
\hline Ana & $\begin{array}{l}\text { Apresentou em sua resolução Registros Monofuncionais com representação } \\
\text { não-discursiva, pois apresentou a construção do gráfico apresentando as } \\
\text { coordenadas com o deslocamento do foguete. Mas também a aluna utiliza } \\
\text { o registro Multifuncional de representação não-discursiva quando usa a fala } \\
\text { para descrever que o software auxilia na compreensão do exercício. }\end{array}$ \\
\hline Maria & $\begin{array}{l}\text { Apresentou em sua resolução Registros Monofuncionais de representação } \\
\text { discursiva quando fez uso de resoluções algébricas para resolver o } \\
\text { problema. A acadêmica também usou do Registro Multifuncional Discursivo } \\
\text { quando argumentou para justificar a sua resolução. }\end{array}$ \\
\hline Pedro & $\begin{array}{l}\text { Apresentou em sua resolução Registros Multifuncionais de Representação } \\
\text { Discursiva, pois iniciou com operações algébricas e posteriormente } \\
\text { desenvolveu Registros Monofuncionais não-discursivos, quando o gráfico do } \\
\text { deslocamento do foguete. }\end{array}$ \\
\hline André & $\begin{array}{l}\text { Utilizou Registros Monofuncionais de Representação Discursivos, pois } \\
\text { apresentou somente operações algébricas para resolver o problema } \\
\text { proposto. }\end{array}$ \\
\hline
\end{tabular}

Fonte: Dados da pesquisa.

\section{5.-Conclusão.}

Este trabalho nos permitiu estimular as possibilidades de resolução das equações algébricas tendo como alvo os estudantes do PIBID do curso de Licenciatura em Matemática. Além disso, proporcionamos uma discussão sobre este tema em Educação Matemática, visando a estimular uma constante construção do conhecimento.

Duval (2011) explica essa dificuldade dos alunos em compreender as diferentes representações de um objeto matemático, pois elas não explicam ou representam a mesma coisa de um objeto matemático.

Nesse contexto observamos que são apresentados diferentes olhares sobre um mesmo objeto matemático que nos ajudam na construção de um cenário que nos permite construir o nosso próprio conhecimento, com base em nossas experiências e conclusões acerca das representações apresentadas.

Salientamos também o caráter dinâmico do software como uma possibilidade de formatação e registro semiótico, que contribui também, aliado aos demais, para a construção do conhecimento.

Diante dos dados obtidos na pesquisa, observamos com base nas colocações de Duval a importância da utilização de diversas representações semióticas e de suas conversões para o aprendizado da Matemática. Com isso estaremos contribuindo para que o nosso aluno desenvolva o seu processo cognitivo, melhorando sua capacidade de raciocínio, interpretação, visualização e análise. 
Como professora de duas disciplinas de informática no curso de licenciatura em Matemática da Universidade do Estado de Mato Grosso e autora desta pesquisa, me permiti realizar uma prática-reflexiva, com relação à teoria das representações semióticas no ensino de matemática e a integração das tecnologias nesse processo. Espero que esta pesquisa motive pesquisadores a desenvolver pesquisas que envolvam múltiplas áreas do conhecimento.

Este contexto nos dá indícios de que o uso da historicidade, das relações teóricopráticas e do uso de software GeoGebra no ensino de Geometria Analítica podem contribuir para a melhor compreensão ou ressignificação dos conceitos de ponto, coordenadas e equação da reta.

Como resultados futuros, esperamos que este trabalho venha salientar a diversificação de metodologias de ensino da Matemática e a multiplicidade de estratégias que podem ser realizadas, integrando a história da matemática e as tecnologias.

\section{6.-Bibliografia.}

Almouloud, S., Fusco, C.A.S. (2010). Provas e demonstrações em matemática: uma questão problemática nas práticas docentes no ensino básico. $X$ Encontro Nacional de Educação Matemática Educação Matemática, Cultura e Diversidade. Bahia: Cortês.

Boero, P., Pedemonte, B., Robotti, E. (1997). Approaching Theoretical Knowledge through Voices and Echoes: a Vygotsky perspective. (2017). Recuperado de: https://www.researchgate.net/profile/Paolo_Boero2/publication/239864337.

Bogdan, R.C., Biklen, S. k. (1994). Investigação qualitativa em educação. Porto: Atlântica.

Borba, M.C. (2010). Informática e Educação Matemática. Belo Horizonte: Autêntica.

Descartes, R. (2001). A Geometria. Tradução Emídio, C.Q.L. Lisboa: Editorial Prometeu.

Duval, R. (2011). Ver e ensinar a Matemática de outra forma: entrar no modo matemático de pensar os registros de representações semióticas. São Paulo: Proem.

Exame Nacional do Ensino Médio. (2010). INEP. Instituto Nacional de Estudos e Pesquisas Educacionais Anísio Teixeira. Ministério da Educação. ENEM: Caderno 7 Azul, Questão 142, p. 20. 
Isoda, M. (2000). Inquiring mathematics with history and software. History in mathematics educacion. The ICMI study. Dodrecht, Boston, London: Kluwer Academic Publisher.

Miguel, A., Miorin, M.A. (2011). História na Educação Matemática: uma proposta e desafios. 2. ed. Coleção Tendências em Educação Matemática10. Belo Horizonte: Editora Autêntica.

Parâmetros Curriculares Nacionais. (2002). Ensino Médio. Brasília: MEC.

Silva, C.M.S. Sad. Lígia, A. (2007). Uma abordagem pedagógica do uso de fontes originais em história da matemática. Coleção História da Matemática para Professores. Guarapuava: SBHMat.

Thomaidis, Y. (1991). Historical digressions in Greek geometry lessons: For the learning of mathematics. vol.11, n.2, p.37-43.

Uberjara, P.M.G. (2004). Los Origenes de La Geometria Analitica. 1. ed. Fundación Canária Orotava de História de la Ciencia: Colecion Materiales de História de la Ciência v.6, n.3, p.54. 